\title{
Can Arbitrary Beliefs Be Rational?
}

\author{
Mattias Skipper \\ Penultimate draft, forthcoming in Episteme
}

\begin{abstract}
When a belief has been influenced, in part or whole, by factors that, by the believer's own lights, do not bear on the truth of the believed proposition, we can say that the belief has been, in a sense, arbitrarily formed. Can such beliefs ever be rational? It might seem obvious that they can't. After all, belief, supposedly, "aims at the truth." But many epistemologists have come to think that certain kinds of arbitrary beliefs can, indeed, be rational. In this paper, I want to do two things. First, I want to show that the claim that arbitrary beliefs can be rational is inconsistent with the conjunction of two other attractive claims: one saying that rationality requires a certain kind of epistemic immodesty, and one saying that rationality forbids certain kinds of self-ascriptions of epistemic luck. Second, I want to evaluate different ways one might respond to this inconsistent triad. I won't defend any response in particular, but I'll draw out some notable costs and benefits of each response, which may help shed light on the question of whether arbitrary beliefs can be rational.
\end{abstract}

Keywords: Arbitrary beliefs, Immodesty, Epistemic luck, Permissivism, Irrelevant influences

\section{Introduction}

Put yourself in the following situation:

Police Corruption: You believe that the Federal Police are corrupt. At the same time, you realize that, had you grown up in a different neighbourhood, you most likely wouldn't have believed that the Federal Police are corrupt. What's more, bracketing your beliefs about police corruption, you don't take yourself to have any reason to think that the neighbourhood in which you grew up is any more likely to have given you true beliefs about such matters as whether the Federal Police are corrupt than any other neighbourhood in which you might have grown up. Yet, you continue to believe that the Federal Police are corrupt.

It's easy to feel a bit uneasy about your belief in this situation. There seems to be something arbitrary about it. But is it, necessarily, irrational? That's the question that interests me here.

The question takes on a more general form. Let's say that when a belief has been influenced, in part or whole, by factors that, by the believer's own lights, do not bear on the truth of the believed proposition, the belief has been arbitrarily formed. The more general question is: Can such beliefs ever be rational?

It might seem obvious that they can't. After all, belief, supposedly, "aims at the truth." But many epistemologists have come to think that certain kinds of arbitrary beliefs can, 
indeed, be rational. As we'll see, they don't all agree about which arbitrary beliefs can be rational, and why. But they all agree that arbitrary beliefs can at least sometimes be rational.

In this paper, I want to do two things. First, I want to show that the claim that arbitrary beliefs can be rational is inconsistent with the conjunction of two other attractive claims: one saying that rationality requires a certain kind of epistemic immodesty, and one saying that rationality forbids certain kinds of self-ascriptions of epistemic luck. Second, I want to evaluate different ways one might respond to this inconsistent triad. I won't defend any response in particular, but I'll draw out some notable costs and benefits of each response, which may help shed light on the question of whether arbitrary beliefs can be rational.

After clarifying the notion of arbitrary belief that I want to focus on ( $(2)$, I'll review some prevalent reasons to think that arbitrary beliefs can be rational (\$3). I'll then go on to show that the view that arbitrary beliefs can be rational is jointly inconsistent with the aforementioned views about epistemic immodesty and self-ascriptions of epistemic luck ( $\$ 4)$. Finally, I'll examine different possible responses to this inconsistent triad ( $(5)$, and draw together some general lessons (\$6).

\section{Preliminaries on Arbitrary Beliefs}

Above I characterized arbitrary beliefs as "beliefs that have been influenced, in part or whole, by factors that, by the believer's own lights, do not bear on the truth of the believed proposition." This hopefully gave the reader an initial sense of the phenomenon that we'll be concerned with. In this section, I want to say a bit more about the notion of arbitrary belief. I won't try to give precise, necessary and sufficient conditions for when a belief has been, in the relevant sense, arbitrarily formed. The aim is just to say enough to enable us to distinguish the relevant notion of arbitrary belief from other natural senses in which a belief might be said to be, or not to be, arbitrary.

Let me begin with an observation that, although elementary, is nonetheless worth keeping in mind, namely that it's often a matter of accident what evidence we have at our disposal-it depends on our upbringing, education, social circle, and countless other factors that lie (at least partly) beyond our control. Here is a familiar example from the history of science:

Heliocentrism: You believe that the earth circles the sun. At the same time, you realize that, had you been born in a different historical era-say, Paleolithic times-you wouldn't have had the kind of extensive evidence about the earth's movement relative to the sun that you in fact have, and hence wouldn't have believed that the earth circles the sun. Yet, you continue to so believe.

I take it that there is a recognizable sense in which your belief in this case might be said to be arbitrary. After all, it is, in a sense, arbitrary or accidental that you should end up with an extensive body of evidence about the earth's movement relative to the sun. However, this is not the kind of arbitrariness that will concern us here. It's uncontroversial that it can be 
rational to believe what your evidence supports, even if it was a matter of accident that you came to possess that evidence. The question we'll be interested in is whether it can be rational to have a belief that has been influenced by factors that, by your own lights, do not bear on the truth. ${ }^{1}$

Next, I'd like to clarify what I mean by saying that arbitrary beliefs are ones that have been influenced by factors that, by the believer's own lights, do not bear on the truth. Consider the following modified version of Police Corruption:

Modified Police Corruption: You believe that the Federal Police are corrupt. However, if you had grown up in a different neighbourhood, you wouldn't have believed that the Federal Police are corrupt. What's more, the neighbourhood in which you actually grew up is, unbeknownst to you, no more likely to have given you true beliefs about such matters as whether the Federal Police are corrupt than any other neighbourhood in which you might have grown up. Yet, you continue to believe that the Federal Police are corrupt.

Again, I take it that there is a recognizable sense in which your belief that the Federal Police are corrupt might be said to be arbitrary. After all, it is, in a sense, arbitrary or accidental that you should end up in this neighbourhood rather than that. But again, this is not the kind of arbitrariness that will concern us here. The reason for this is largely dialectical: if it can be rational to have beliefs that have been influenced by factors that, by your own lights, do not bear on the truth, it can presumably also be rational to have beliefs that have been influenced by factors that, unbeknownst to you, do not bear on the truth. In other words, someone who thinks that the latter kind of arbitrary beliefs can be rational should presumably also think that the former kind of arbitrary beliefs can be rational. By contrast, it's not clear that someone who denies that the former kind of arbitrary beliefs can be rational should also deny that the latter kind of arbitrary beliefs can be rational. Indeed, the inconsistent triad that I'll bring out below pertains only to the former kind of arbitrary beliefs. This is why, as a matter of stipulation, I'll count cases like Police Corruption, but not cases like Modified Police Corruption, as cases of arbitrary belief.

\footnotetext{
${ }^{1}$ It's perhaps not immediately clear why your belief that the earth circles the sun doesn't count as having been influenced by factors that, by your own lights, do not bear on the truth. After all, you wouldn't have believed that the earth circles the sun if you had grown up in Paleolithic times; and, by your own lights, the historical era in which you grew up has no bearing on the whether the earth circles the sun. Doesn't this show that there's at least $a$ sense in which your belief that the earth circles the sun has been influenced by factors that, by your own lights, do not bear on the truth? I think so. However, in the Heliocentrism case, you take yourself to be in a better evidential position than you would have been in, if you had grown up in Paleolithic times. By contrast, in the Police Corruption case, you don't take yourself to be in a better evidential position than you would have been in, if you had grown up in a different neighbourhood. For our purposes here, that's the crucial difference between Police Corruption and Heliocentrism.
} 
Finally, I'd like to draw attention to a type of belief formation that I do want to classify as arbitrary, although there's a natural sense in which it might be said not to be arbitrary. To illustrate the phenomenon I have in mind, consider the following scenario:

Extreme Sapere Aude: You've grown up in a society in which it is customary to place no weight on testimonial evidence. Think for yourself?, is the society's slogan, and it is held sacred by all citizens in word and deed. You're no exception: when someone tells you that $p$, you don't let it affect your credence in $p$. At the same time, you realize that, had you grown up in a different society, you would most likely have placed significant weight on testimonial evidence. What's more, you don't take yourself to have any independent reason to think that the society in which you grew up is any more likely to have a truthconducive way of accommodating testimonial evidence than any other society in which you might have grown up. Yet, you continue to place no weight on testimonial evidence.

Here there's a natural sense in which your beliefs haven't been arbitrarily formed. After all, they've been formed in accordance with a general principle about how to accommodate testimonial evidence. As it is sometimes put: you've been living up to your own epistemic standards. ${ }^{2}$ I'll return to the notion of epistemic standards later, and how it relates to the question of whether arbitrary beliefs can be rational. For now, the important point is that, in the Extreme Sapere Aude case (as I've described it), you don't take yourself to have any independent reason to think that your own epistemic standards are any more truth-conducive than whatever other epistemic standards you might have had, if you had grown up in a different society. This is what makes Extreme Sapere Aude relevantly similar to Police Corruption: in both cases, your belief state has been influenced by factors that, by your own lights, do not bear on the truth.

These preliminary remarks clearly don't amount to anything like a precise definition. But I hope that they go at least some way towards fixing the class of arbitrary beliefs that I want to focus on. Next, I'd like to consider some of the most prevalent reasons why many epistemologists have come to think that such arbitrary beliefs can be rational.

\section{Why Think That Arbitrary Beliefs Can Be Rational?}

Let Rational Arbitrariness be the thesis that arbitrary beliefs, as characterized above, can be rational. Why think that Rational Arbitrariness is true? There are at least two general lines of argument, which have emerged from the recent epistemological literature. In their simplest form, they may be stated as follows:

The Road from Permissivism: Rational Arbitrariness is true, since it follows from certain plausible assumptions about the extent to which rationality is permissive.

\footnotetext{
${ }^{2}$ See, e.g., White (2005, §3), Schoenfield (2014), Kopek and Titelbaum (ms.), Li (2019b).
} 
The Road from Anti-skepticism: Rational Arbitrariness is true, since its negation leads to absurd skeptical consequences.

Below, I'll describe each of these arguments in a bit more detail. I don't want to suggest that they constitute the only (or even the best) arguments for Rational Arbitrariness. ${ }^{3}$ The aim is just to give the reader at least a rough sense of why someone might be attracted to the view that arbitrary beliefs can be rational.

\subsection{The Road from Permissivism}

Let's say that an epistemic situation is permissive just in case there is more than one rationally permissible belief state to adopt in that situation. And let Epistemic Permissivism be the thesis that some epistemic situations are permissive. ${ }^{4}$ In recent years, a number of arguments have been offered in support of Epistemic Permissivism: some authors have argued that rational people can disagree even when confronted with the same body of evidence (Rosen 2001, p. 71; Schoenfield 2014, \$2.1); others have argued that rationality permits different trade-offs between the "Jamesian goals" of believing what is true and not believing what is false (Kelly 2013; Pettigrew ms); and still others have defended Epistemic Permissivism on the grounds that some belief states are epistemically supererogatory (Li 2018, 2019a; Jackson 2019). Needless to say, not everyone has been persuaded by these arguments. Indeed, a number of attempts have been made at defending the negation of Epistemic Permissivism (a thesis commonly known as "The Uniqueness Thesis"). ${ }^{5}$ My aim here is not to weigh and compare the various arguments for and against Epistemic Permissivism tha have been put forth. Rather, I'm interested in the connection between Epistemic Permissivism and Rational Arbitrariness.

So what is the connection between Epistemic Permissivism and Rational Arbitrariness? Epistemic Permissivism doesn't straightforwardly entail Rational Arbitrariness, but it does so when combined with two additional claims, which many permissivists will be inclined to accept. The first claim is this:

Acknowledged Permissivism: If it's possible to be in a permissive situation, it's possible to realize that you're in a permissive situation.

\footnotetext{
3 Indeed, we'll later (in \5.1) consider an alternative way of motivating Rational Arbitrariness, which appeals to a distinction between precise and imprecise credences.

${ }^{4}$ As stated, Epistemic Permissivism is a fairly schematic view, which can be developed in different ways, depending on how one answers various more specific questions, such as: How widespread are these alleged permissive situations? How much can different permissible belief states differ? What makes a permissive situation permissive in the first place? And so on. For present purposes, we don't need to delve into these further questions — what I'll have to say about Epistemic Permissivism won't turn on the finer details of the view. Interested readers may consult, e.g., White (2005), Podgorski (2016), Jackson (2019), and Pettigrew (ms.). ${ }^{5}$ See, e.g., White (2005), Feldman (2007), Dogramaci \& Horowitz (2016), and Schultheis (2018).
} 
In other words, according to Acknowledged Permissivism, if it's possible to be in a permissive situation, it's possible to know which belief states are permitted in your situation. ${ }^{6}$ This is not to say that it's always possible to know which belief states are permitted in your situation, although some permissivists might want to defend this stronger claim as well. The claim is just that permissive situations, insofar as they exist, aren't systematically "elusive" in the sense that you can never know that you're in one.

Acknowledged Permissivism is rarely discussed in depth, but a number of participants in the permissivism debate have, if not outright endorsed it, at least found it prima facie plausible. ${ }^{7}$ Understandably so-it's hard to see why it should be in-principle impossible to learn that you're in a permissive situation, or why learning that you're in a permissive situation should somehow turn your situation into a non-permissive one. There might be a way to defend a view along these lines. ${ }^{8}$ I certainly don't want to foreclose this possibility. But I suspect that most permissivists would be inclined to accept Acknowledged Permissivism.

Here is the second claim:

Permissive Parity: If you realize that you're in a permissive situation, you shouldn't take yourself to have independent reasons to think that one permissible belief state is more accurate than another.

In other words, according to Permissive Parity, if you realize that you're permitted to be in either of two belief states, B and B', you shouldn't take yourself to have independent reasons (independent, that is, from the belief state you actually adopt) to think that B is more accurate than B', or vice versa. In that sense, different permissible belief states are "on a par" with respect to their accuracy.

Like Acknowledged Permissivism, Permissive Parity is rarely discussed in depth. However, some authors seem to assume it in the background, ${ }^{9}$ and I suspect that many others would be inclined to accept it. Consider, for example, a Subjective Bayesian who thinks that there is more than one permissible prior credence function (that is, more than one permissible set of conditional and unconditional credences prior to getting any evidence). ${ }^{10}$ On such a view, there are presumably no independent, accuracy-based reasons to adopt one permissible prior over another. Rather, different permissible priors are permissible precisely because they are on a par with respect to their accuracy.

Or consider someone who thinks that there's more than one permissible trade-off between the "Jamesian goals" of believing what is true and not believing what is false (see, e.g., Kelly

\footnotetext{
${ }^{6}$ The label "Acknowledged Permissivism" is from Titelbaum \& Kopec (ms., p. 15). The distinction between acknowledged and unacknowledged permissive cases can also be found in earlier papers by Ballantyne \& Coffman (2012, p. 663) and Cohen (2013).

${ }^{7}$ See, e.g., Schoenfield (2014, fn 31), White (2005, p. 450), and Ye (2020).

${ }^{8}$ For a recent attempt to do so, see Smith (2020). See also Li (2019a, \4) for a critical discussion of different ways one might try to resist Acknowledged Permissivism.

${ }^{9}$ See, e.g., White $(2005, \$ 2)$ and Schoenfield (2014, fn. 20).

${ }^{10}$ Such a brand of permissivism is defended by, e.g., Meacham (2013) and Pettigrew (ms.).
} 
2013). On such a view, there are presumably no independent, accuracy-based reasons to adopt one permissible trade-off over another. Rather, an agent's trade-off is supposed to reflect something like the agent's preferred level of "epistemic risk-aversion:" roughly, how much the agent cares about being right and not being wrong in her beliefs, respectively.

I don't mean to suggest that all permissivists would be prepared to accept Permissive Parity. Consider, for example, someone who thinks that Epistemic Permissivism is true because some belief states are epistemically supererogatory in roughly the sense that they go beyond what is minimally required for a belief state to be rationally permissible. ${ }^{11} \mathrm{~A}$ proponent of such a view might want to deny Permissive Parity, at least in its unrestricted form. To see why, consider a situation in which there are just two permissible belief states, B and B', where B is supererogatory and B' is not. If the agent in fact adopts the supererogatory belief state, $\mathrm{B}$, it might well be reasonable for her to take herself to have independent, accuracy-based reasons for adopting B rather than B'. After all, it's natural to think that whatever made B supererogatory also makes B more likely to be accurate.

So, I don't want to claim that all proponents of Epistemic Permissivism should accept Acknowledged Permissivism and Permissive Parity. But those who do are committed to Rational Arbitrariness as well. Here is why: Consider a situation in which an agent is permitted to adopt either of two belief states, B and B'. If Epistemic Permissivism is true, such a situation is possible. And, by Acknowledged Permissivism, we may assume that the agent realizes that B and B' are both permissible. Moreover, by Permissive Parity, the agent shouldn't take herself to have independent, accuracy-based reasons to adopt B rather than B', or vice versa. So, whatever belief state the agent adopts, the belief state will have been, in the relevant sense, arbitrarily formed: it will have been influenced by factors that, by the agent's own lights, do not bear on the truth. In sum: if Epistemic Permissivism, Acknowledged Permissivism, and Permissive Parity are true, then so is Rational Arbitrariness.

\subsection{The Road from Anti-skepticism}

The second line of argument for Rational Arbitrariness takes the form of a reductio: denying Rational Arbitrariness leads to absurd skeptical consequences, so Rational Arbitrariness must be true. There are different ways one might try to develop this anti-skeptical line of argument, but one natural way takes as its starting point a familiar skeptical challenge: that of providing independent justification for one's most fundamental epistemic standards. ${ }^{12}$

Roughly speaking, epistemic standards are supposed to encode different ways an agent might respond to different bodies of evidence. For example, within a Bayesian framework, we may think of an agent's epistemic standards as encoded in the agent's prior credence

\footnotetext{
11 Versions of this view have been defended by Li (2018; 2019a) and Jackson (2019). See also Podgorski (2016, \$4.4) for a related proposal.

${ }^{12}$ Versions of this line of argument can be found in, e.g., Elga (ms.), White (2010), and Schoenfield (2014).
} 
function. More generally, we may think of an agent's epistemic standards as a function from epistemic situations to belief states, representing which belief state the agent would adopt if put in a given epistemic situation.

Several authors have argued for Epistemic Permissivism on the grounds that there can be more than one permissible set of epistemic standards. ${ }^{13}$ But even without taking a stance in the permissivism debate, we can motivate Rational Arbitrariness by appeal to some fairly general considerations about the kinds of reasons one might have (or not have) to think that one's own epistemic standards are reliable.

Imagine that you encounter a skeptic who challenges you to justify your own epistemic standards in a non-circular way, that is, in a way that doesn't presuppose the reliability of those very standards. Here is one way such an encounter might go: after a bit of reflection, you concede to the skeptic that you're unable to meet the challenge, not because you think that there's anything especially defective about your own epistemic standards, but because you've come to the conclusion-say, on the basis of familiar regress considerations- that it's impossible for anyone to justify their own fundamental epistemic standards without relying on those very standards. ${ }^{14}$ In light of this concession, the skeptic urges you to give up your ordinary beliefs and enter a state of radical skeptical doubt. But you resist. Instead, you maintain your ordinary beliefs, and acknowledge that you don't have any independent reason to think that the epistemic standards by which those beliefs have been formed are reliable.

Now if that's how you respond to the skeptic, your belief state has been, in the relevant sense, arbitrarily formed: it has been influenced by a set of epistemic standards that you don't take yourself to have any independent reason to think is more reliable than any other set of epistemic standards you might have had. So, if your response to the skeptic is rational, this would suffice to establish Rational Arbitrariness.

But is it? Many epistemologists think so. They maintain that even if we can't provide independent justification for our most fundamental epistemic standards, we're not rationally required to enter a state of radical skeptical doubt for that reason. ${ }^{15}$ Needless to say, there are worries one might have about this sort of anti-skeptical position, and I certainly don't want to endorse it here. The aim of these brief remarks is just to convey why some epistemologists have been led by general anti-skeptical concerns to accept the view that a certain kind of arbitrary belief formation can be rational.

\section{An Inconsistent Triad}

We've now seen why someone might find Rational Arbitrariness attractive. The next task is to show that Rational Arbitrariness is jointly inconsistent with two other attractive claims:

\footnotetext{
13 See, e.g., Kelly (2013), Schoenfield (2014), and Titelbaum \& Kopec (ms.).

14 See Elga (ms.), White (2010, p. 604), and Schoenfield $(2014, \$ 2.2)$ for further elaboration on this point.

15 This sort of anti-skeptical view has a long history. In recent decades, it has been prominently defended by, e.g., Pryor (2000) and Wright (2004).
} 
the claim that rationality requires a certain kind of immodesty, and the claim that rationality forbids certain kinds of self-ascriptions of epistemic luck. I'll begin by briefly introducing each of these claims ( $\mathbb{S}$ 4.1-4.2), before explaining why they form an inconsistent triad together with Rational Arbitrariness (\$4.3).

\subsection{Epistemic Immodesty}

Following Lewis (1971), let's say that you're immodest just in case you expect your own belief state to be more accurate than any specific alternative belief state. And let Immodesty be the thesis that you should be immodest. So stated, Immodesty is a fairly generic thesis which may be precisified in different ways, depending on how we represent an agent's belief state. On the most common such precisification, an agent's belief state is represented by a (sharp) credence function, which is said to be immodest just in case it expects itself to be more accurate than any specific alternative credence function. ${ }^{16}$ Readers who are familiar with this way of defining Immodesty are welcome to apply it below, but the finer details of how to define Immodesty won't matter for present purposes.

Why think that Immodesty is true? Perhaps the most frequently cited reason is that there seems to be something "unstable" or "self-undermining" about having a belief state that one takes to be less accurate than some specific alternative belief state. After all, if you really did think that some other belief state was more accurate than your own, why not adopt it instead? Here is Lewis (1971) making essentially this point:

[W]ould non-immodesty give you any good reason not to trust an inductive method? Indeed it would. Suppose you did trust some non-immodest method. By definition, it estimates some competing method to be more accurate than itself. So if you really did trust your original method, you should take its advice and transfer your trust to one of the competing methods it recommends. (Lewis 1971, p. 56)

Let's not worry about what, exactly, Lewis meant by "inductive method" here. ${ }^{17}$ The important point for present purposes is that the same can be said about belief states: if your belief state estimates some competing belief state to be more accurate than itself, then, if you really did trust your own belief state, it seems that you should take its advice and transfer to the competing belief state instead.

This may seem plausible enough. But it doesn't quite get us all the way to Immodesty. It only gets us something weaker: that you should expect your own belief state to be no less accurate than any other belief state. For as long as you take your own belief state to be among

\footnotetext{
${ }^{16}$ The expected accuracy of a credence function, $\mathrm{Cr}_{1}$, calculated with respect to a (possibly identical) credence function, $\mathrm{Cr}_{2}$, is the average of the accuracy of $\mathrm{Cr}_{1}$ at different possible worlds, weighted by the probability assigned by $\mathrm{Cr}_{2}$ to those worlds obtaining.

${ }^{17}$ Formally, Lewis defines inductive methods in the same way that (conditional) credence functions are usually defined: as mappings from pairs of propositions to real numbers between 0 and 1 (Lewis 1971, p. 54).
} 
the most accurate ones, there isn't obviously anything unstable or self-undermining about your belief state. ${ }^{18}$

However, a recent result by Campbell-Moore \& Levinstein (2021) shows that the weak version of Immodesty in fact entails the strong version, given some fairly minimal background assumptions, which many proponents of Immodesty are willing to accept. ${ }^{19}$ It would take us too far afield to review the formal details of this result (an informal sketch of the argument is included in a footnote) ${ }^{20}$ Suffice it to say that, insofar as Lewis's stability considerations are taken to motivate the weak version of Immodesty, they should arguably be taken to motivate the strong version of Immodesty as well.

A second line of motivation for Immodesty worth mentioning comes from the "accuracy-first" program in epistemology, instigated by Joyce (1998) and fruitfully developed by Pettigrew (2016) and others. It is well-known that many of the central results in this areaincluding those employed by Joyce (1998) and Greaves \& Wallace (2006) to defend Probabilism and Conditionalization, respectively-rely crucially on Immodesty. ${ }^{21}$ Whether, or to what extent, this should be taken to lend support to Immodesty obviously depends on how promising one finds the accuracy-based approach to epistemology in the first place. But those who are moved by accuracy-based arguments may reasonably take themselves to have broadly abductive reasons to accept Immodesty.

\subsection{Self-Ascriptions of Epistemic Luck}

The final ingredient needed for our inconsistent triad is the view that rationality forbids certain kinds of self-ascriptions of epistemic luck. To illustrate the phenomenon I have in mind, consider an example due to Roger White (2005, pp. 447-48):

\footnotetext{
18 This point has been appreciated by a number of authors, including Pettigrew (2011, \4.1), Mayo-Wilson and Wheeler (2016, p. 65), and Campbell-Moore \& Levinstein (2021, p. 10).

19 The first assumption is known as "Truth-directedness" and says, roughly, that the closer your credences are to the truth, the more accurate they are. The second assumption is known as "Additivity" and says, roughly, that the overall accuracy of your credence function at a given world is just the sum of the accuracy of each of your credences in different propositions at that world. Both assumptions are usually taken for granted within accuracy-first epistemology, though see Pettigrew (forthcoming) for a recent criticism of Additivity.

${ }^{20}$ For simplicity, consider just a single proposition, $p$, and consider two distinct credence functions, $\mathrm{Cr}_{1}$ and $\mathrm{Cr}_{2}$, such that $\mathrm{Cr}_{1}$ expects itself to be at least as accurate as $\mathrm{Cr}_{2}$ with respect to $p$. Since $\mathrm{Cr}_{1}$ and $\mathrm{Cr}_{2}$ are distinct, $\mathrm{Cr}_{1}(p) \neq \mathrm{Cr}_{2}(p)$. Suppose, without loss of generality, that $\mathrm{Cr}_{1}(p)<\mathrm{Cr}_{2}(p)$. We can then find a number $x: \mathrm{Cr}_{1}(p)$ $<x<\mathrm{Cr}_{2}(p)$. Now consider a third credence function $\mathrm{Cr}_{3}: \mathrm{Cr}_{3}(p)=x$. By Truth-directedness, $\mathrm{Cr}_{1}$ must expect $\mathrm{Cr}_{3}$ to be strictly more accurate than $\mathrm{Cr}_{2}$ with respect to $p$. And, by weak Immodesty, $\mathrm{Cr}_{1}$ must expect itself to be at least as accurate as $\mathrm{Cr}_{3}$ with respect to $p$. So, $\mathrm{Cr}_{1}$ must expect itself to be strictly more accurate than $\mathrm{Cr}_{2}$ with respect to $p$. As Campbell-Moore and Levinstein show, by adding Additivity, this line of argument can be generalized to credence functions which are defined over a full algebra.

${ }^{21}$ More precisely, they rely on the assumption that the accuracy of credence functions is to be measured using a strictly proper scoring rule, that is, a scoring rule that has the property that every probabilistic credence function is immodest.
} 
Belief-Inducing Pills: You have no idea whether $p$. But you have a couple of magical belief-inducing pills. One, when swallowed, will give you a true belief about $p$, the other a false belief. You have no idea which one is the Truth pill. Yet, you go ahead and swallow one of the pills at random. Next thing you know, you find yourself believing that $p$. On reflection, you think to yourself: "My belief that $p$ was induced by the pill I swallowed. And $p$ is true. So, I must have swallowed the Truth pill. What luck!"

As White points out, there seems to be something utterly irrational about someone who reasons this way. If this isn't immediately clear, just imagine repeating the process many times over (we may suppose that you've been given a jar full of magical pills, half of which are Truth pills, and half of which are Falsity pills). Each time, you swallow a pill at random, find yourself with a newly minted belief, and conclude that, since your belief is true, you must have swallowed one of the Truth pills. If you do this ten times in a row, you'll end up thinking to yourself: "All ten of my beliefs were induced by a randomly chosen pill. And all ten beliefs are true. So, I must have chosen a Truth pill ten times in a row. But the chance of that happening is a mere $(1 / 2)^{10} \approx 0.1 \%$. What an incredible stroke of luck!" That's absurd. Increase the number of repetitions even further, and we can make the absurdity as vivid as we like.

Let No Luck be the thesis that the kind of self-ascribed epistemic luck exemplified by Belief-Inducing Pills can never be rational. Needless to say, this doesn't amount to a precise definition. But a precise definition won't be needed. Later, I'll provide some further examples of self-ascriptions of epistemic luck, which will be recognizably similar to Belief-Inducing Pills. This will suffice to bring out the inconsistency.

Before we proceed, however, let me clarify two points about what No Luck doesn't say. First, No Luck doesn't say that it's irrational to be epistemically lucky; it just says that it's irrational to self-ascribe the relevant kind of epistemic luck. To illustrate the difference, consider the following modification of Belief-Inducing Pills:

Modified Belief-Inducing Pills: You believe that $p$. For all you can tell, your belief has been formed in an entirely ordinary way (say, on the basis of perception). However, unbeknownst to you, your belief has in fact been induced by a magical pill, which was slipped into your drink last night by an unscrupulous drug scientist. The pill was randomly selected from a jar that contains equal proportions of Truth and Falsity pills. Luckily, you were slipped one of the Truth pills.

Here it may be less clear whether your belief is irrational, as witnessed by the long-standing debate between internalists and externalists about epistemic justification. ${ }^{22}$ Fortunately, we don't have to take a stance on this issue here-No Luck is silent in cases like Modified BeliefInducing Pills.

${ }^{22}$ Classic references in this debate include Goldman (1979), BonJour (1980), and Cohen (1984). 
Second, it's worth distinguishing No Luck from a different kind of anti-luck thesis, which has played a central role in the post-Gettier literature on the nature of knowledge: the thesis that you can't know that $p$ if your belief that $p$ is true merely by luck. ${ }^{23}$ This thesis differs from No Luck in at least two respects: first, it concerns knowledge rather than rational belief; and, second, it says that knowledge is incompatible with being epistemically lucky, not that knowledge is incompatible with self-ascribing the relevant kind of epistemic luck.

\subsection{Why Rational Arbitrariness, Immodesty, and No Luck Are Jointly Inconsistent}

We've now been introduced to three claims-Rational Arbitrariness, Immodesty, and No Luck - and we've seen what makes them attractive. Why are they jointly inconsistent? The answer may already be obvious from what has been said, but here is a fairly general way of bringing out the inconsistency: Consider an agent whose belief state has been, in the relevant sense, arbitrarily formed. If Rational Arbitrariness is true, we can assume that the agent's belief state is rational. And if Immodesty is true, the agent should expect her own belief state to be more accurate than any specific alternative belief state. So, the agent is in a position to reason as follows: "My belief state has been influenced, in part, by factors that don't bear on the truth. Yet, I've ended up with a belief state that is expectedly more accurate than any other belief state I might have ended up with. What luck!" But that's precisely the kind of self-ascribed epistemic luck that No Luck is supposed to deem irrational. So, Rational Arbitrariness, Immodesty, and No Luck can't all be true.

It's worth pausing to consider how this inconsistency can manifest itself in a more concrete case. Take again the Subjective Bayesian who thinks that there is more than one permissible prior, and consider an agent whose credence function is based on one such permissible prior. As explained in \$3.1, the agent's credence function has then been, in the relevant sense, arbitrarily formed: it has been influenced by the agent's prior, which the agent doesn't take herself to have any independent reason to think is more likely to have resulted in accurate credences than any other permissible prior. ${ }^{24}$ And if Immodesty is true, the agent should expect her own credence function to be more accurate than any alternative credence function. So, the agent is in a position to reason as follows: "My credence function has been influenced, in part, by my choice of prior. And I have no independent reason to think that my prior would result in more accurate credences than any other permissible prior. Yet, I've ended up with a credence function that is expectedly more accurate than any other credence function I might have ended up with. What luck!" That's a violation of No Luck.

\footnotetext{
${ }^{23}$ Discussions of this sort of anti-luck thesis can be found in Unger (1968), Zagzebski (1994), Pritchard (2005), among others.

${ }^{24}$ Assuming, for the purposes of illustration, that the permissivist under consideration (here: the Subjective Bayesian) accepts Acknowledged Permissivism and Permissive Parity.
} 
For another example, consider the view that there are different permissible trade-offs between the "Jamesian goals" of believing what is true and not believing what is false, and consider an agent whose belief state is based on one such permissible trade-off. Then again, the agent's belief state has been, in the relevant sense, arbitrarily formed: it has been influenced by the agent's Jamesian trade-off, which the agent doesn't take herself to have any independent reason to think is more likely to result in accurate beliefs than any other permissible tradeoff. By Immodesty, the agent should expect her own belief state to be more accurate than any alternative belief state. So, the agent is in a position to reason as follows: "My belief state has been influenced, in part, by my preferred Jamesian trade-off between the goals of believing what is true and not believing what is false. And I have no independent reason to think that my own trade-off would result in more accurate beliefs than any other permissible trade-off. Yet, I've ended up with a belief state that is expectedly more accurate than any other belief state I might have ended up with. What luck!" Again, that's a violation of No Luck.

The more general pattern should now be clear: any epistemological view which is committed to Rational Arbitrariness will, when combined with Immodesty, inevitably lead to self-ascriptions of epistemic luck. In other words: Rational Arbitrariness, Immodesty, and No Luck are jointly inconsistent. That's the first major upshot of the paper.

\section{Responses to the Inconsistent Triad}

We have an inconsistent triad on our hands. What to do about it? At the highest level of generality, we have three options: we can either deny Immodesty, No Luck, or Rational Arbitrariness. Below, I'll examine each of these options in turn. As mentioned in the introduction, I won't defend any particular response over the others. But I hope to be able to say enough about the costs and benefits of the different responses to allow us to move forward with a better understanding of the tension at hand.

\subsection{Rejecting Immodesty}

One reaction to the inconsistent triad is to give up on the idea that you should always expect your own belief state to be more accurate than any alternative belief state. How might such a response be motivated? The most principled reason to doubt Immodesty, to my knowledge, comes from recent work on imprecise credences. Many epistemologists have claimed that, in response to certain kinds of vague or ambiguous evidence, it can be rational to adopt an imprecise (or "mushy") credence rather than a precise (or "sharp") one. ${ }^{25}$ Imprecise credal states are usually represented by sets of precise credence functions, which together make up what is known as the agent's representor. ${ }^{26}$ So, for example, if you have an imprecise credence in $p$ that spans the interval from $20 \%$ to $30 \%$, your representor will

\footnotetext{
${ }^{25}$ Influential examples include Levi (1985) and Joyce (2005).

26 This term was, I believe, coined by van Fraassen (1990).
} 
include, for each real number $x$ between $20 \%$ and $30 \%$, a precise credence function that assigns a probability of exactly $x$ to $p$ (and no credence function in your representor will assign a probability below $20 \%$ or above $30 \%$ to $p$ ).

Now it remains controversial whether imprecise credences can indeed be rational. ${ }^{27} \mathrm{But}$ if they can, there's arguably good reason to think that we should reject Immodesty, at least in its most general form. A result by Mayo-Wilson \& Wheeler (2016) shows that, given certain background assumptions about how to measure accuracy, the following two claims are true: (i) for every imprecise credence function, there is a precise credence function that is exactly as accurate at every world; and (ii) for every precise credence function, there is an imprecise credence function that is exactly as accurate at every world. ${ }^{28}$ In other words, neither precise nor imprecise credence functions are immodest: they don't expect themselves to be more accurate than every other precise or imprecise credence function.

To interpret this result, it will be helpful to adopt a bit of terminology from Builes et al. (2020): let's say that you contract when you move from an imprecise credence function to a precise credence function, and let's say that you dilate when you move from a precise credence function to an imprecise one. What Mayo-Wilson \& Wheeler's result shows, then, is that it's possible for an agent to contract and dilate arbitrarily - that is, without receiving any new evidence-without incurring any loss of expected accuracy, that is, without at any point moving to a new credal state that, by the agent's current lights, has a lower expected accuracy than the agent's current credal state.

How might this result help us resolve the inconsistent triad? The beginnings of an answer can be found in a paper by Miriam Schoenfield (forthcoming), who entertains the idea that there might be a close relationship between arbitrary belief formation and imprecise credences. More specifically, Schoenfield suggests that when we pause to reflect on the fact that a given belief of ours has been influenced by truth-irrelevant factors, we tend not to adopt a very precise credence on the matter. Rather, we tend to adopt an imprecise credence. And as we've just seen, imprecise credences aren't immodest: they allow us to contract to a precise credence at no loss of expected accuracy. So, even if you realize that your credence on a given matter has been influenced by truth-irrelevant factors, it might still be rational for you to adopt a precise credence on the matter. Indeed, the credence may be opinionated: if you start out being more than $50 \%$ confident of $p$, you may end up being more than $50 \%$ confident of $p$ upon learning that your opinionated credal state was influenced by factors that do not bear on the truth. That's the gist of Schoenfield's proposal, as I understand it.

\footnotetext{
${ }^{27}$ For example, Elga (2010) argues that imprecise credences leave agents "Dutch Bookable."

28 The result builds on a similar result by Seidenfeld, Schervish \& Kadane (2012). A closely related result has also been established by Schoenfield (2017). The background assumptions needed for Mayo-Wilson \& Wheeler's result are: “Admissibility" (roughly, the claim that permissible credence functions aren't accuracydominated), "Extensionality" (roughly, the claim that the accuracy of a credence relative to a proposition and a world is a function only of the credence and the truth-value of the proposition at that world), and "Continuity" (roughly, the claim that the accuracy of a credence relative to a proposition and a world is a continuous function of the credence).
} 
It's natural to wonder what reason there is to think that people tend to adopt an imprecise credal state when reflecting on the fact that their beliefs have been influenced by truth-irrelevant factors. Schoenfield herself doesn't purport to defend this claim by argument, and I won't here try to guess what such an argument might look like. But if Schoenfield's proposal is on the right track, it promises to go at least some way towards resolving the inconsistent triad at hand.

Unfortunately, I don't think it goes far enough. The trouble is that Schoenfield's proposal is still meant to satisfy a restricted version of Immodesty, which applies only at the level of precise credences:

Precise Immodesty: A precise credence function is rational only if it expects itself to be more accurate than any other precise credence function.

This restricted Immodesty principle is enough to generate self-ascriptions of epistemic luck in cases where an agent contracts arbitrarily from an imprecise to a precise credence function. Consider an agent who currently has an imprecise credence function, and let $\mathrm{Cr}_{1}$ and $\mathrm{Cr}_{2}$ be any two precise credence functions in the agent's representor. Now suppose that the agent contracts arbitrarily to $\mathrm{Cr}_{1}$. By Precise Immodesty, the agent should now-after having contracted-expect $\mathrm{Cr}_{1}$ to be more accurate than $\mathrm{Cr}_{2}$. But since the agent contracted arbitrarily, she didn't take herself to have any accuracy-based reasons for contracting to $\mathrm{Cr}_{1}$ rather than $\mathrm{Cr}_{2}$. So, the agent must consider herself lucky to have contracted to $\mathrm{Cr}_{1}$ rather than $\mathrm{Cr}_{2}$. Thus, even if we deny Immodesty in its most general form, we still run into violations of No Luck if we combine Precise Immodesty with the view that it can be rational to contract arbitrarily from imprecise to precise credences. Schoenfield's proposal ultimately leaves the inconsistent triad intact. ${ }^{29}$

\subsection{Rejecting No Luck}

A different reaction to our inconsistent triad is to concede that self-ascriptions of epistemic luck, odd as they may seem, can nonetheless be rational. This response has been perhaps most explicitly endorsed by Adam Elga (ms.) in an unpublished paper entitled "Lucky to Be Rational." ${ }^{30}$ In brief outline, Elga's argument goes as follows: Consider a rational agent who learns that their most fundamental epistemic standards were determined by arbitrary factors. If it isn't clear that a rational agent could undergo such a learning experience, put yourself in the following scenario (with homage to a certain famous physicist): ${ }^{31}$

\footnotetext{
${ }^{29}$ Thanks to an anonymous referee for help with the framing of this section.

30 See also White $(2010$, \$4.3) and Schoenfield (2014, fn. 20).

31 Readers who prefer a less divine example may replace "God" by "Mother Nature" and replace "throw of a die" by any naturalistically kosher chance process.
} 
God Plays Dice: God created you with an epistemic standard, which was chosen on the basis of a throw of a fair die. If the die came up even, God gave you a reliable epistemic standard; if not, not. God tells you that this is how your epistemic standard was determined, but you have no clue about whether the die came up even or odd. In fact, it came up even.

How should you react upon learning how your epistemic standard was determined? It's natural to think that you should lose confidence in the reliability of your own epistemic standard-after all, you have no idea of whether the die came up even or odd. But as Elga points out, if you did lose confidence in the reliability of your own epistemic standard, it would have to be your epistemic standard itself that recommended this response-after all, an agent's epistemic standard is supposed to govern the agent's response to any new evidence, including evidence about how the agent came to possess that standard. In other words, your epistemic standard would have to be modest: it would have to recommend doubting its own reliability. So, on pain of violating Immodesty, you shouldn't lose confidence in your own epistemic standard after all. Rather, you should stand behind your own epistemic standard, and consider yourself lucky to have ended up with that standard. That's the gist of Elga's argument.

There are different ways one might try to push back against this argument. For example, Schechter (ms., pp. 7-8) points out that if it's never rational to doubt one's most fundamental epistemic standards, those standards would seem to be immune to criticism, which might seem counterintuitive. ${ }^{32}$ I don't want to pursue this line of criticism. The more important point here is that Elga's motivation for rejecting No Luck ultimately derives from his motivation for accepting Rational Arbitrariness and Immodesty. In other words, the reason why Elga thinks that we have good reason to accept that self-ascriptions of epistemic luck can be rational is that he thinks that we have good reason to accept Rational Arbitrariness and Immodesty. This isn't a problem in and of itself. But it means that Elga's argument won't be dialectically effective against someone who hasn't yet made up their mind about how to resolve the inconsistent triad at hand. Those of us who are in this situation are looking for ways to resolve the inconsistent triad, which don't depend on whatever reason we had for accepting each of the three inconsistent theses in the first place.

Admittedly, it's not clear what a suitably independent argument against No Luck might look like. The claim that self-ascriptions of epistemic luck are irrational seems to capture a pretty basic intuition. But even if we can't argue against No Luck from more basic principles, it might still be possible to offer some sort of explanation (or "error theory") of why we'd be inclined to think that self-ascriptions of epistemic luck are irrational, when in fact they are not. To my knowledge, no such explanation has been offered in the literature, and I have no

\footnotetext{
${ }^{32}$ See also Schechter $(2013, \$ 4.2)$ for a discussion of this point.
} 
proposal here for how to provide it. ${ }^{33}$ But without such an explanation, it seems to me that denying No Luck involves an egregious amount of bullet-biting.

\subsection{Rejecting Rational Arbitrariness}

Perhaps, then, we should deny that arbitrary beliefs can be rational in the first place. In light of what has been said, this might seem like the least radical solution to the problem at hand. After all, the central motivations for Rational Arbitrariness reviewed in $\$ 3$ all rely on broadly theoretical considerations, which may be denied without flying in the face of normative common sense.

But even if denying Rational Arbitrariness doesn't do any immediate violence on our intuitions, we're still left with a major task of explaining where the different arguments for Rational Arbitrariness go wrong. This isn't a task I can possibly hope to do justice to here. As we've seen, the considerations that have persuaded epistemologists that arbitrary beliefs can be rational are bound up with some notoriously difficult questions that are best dealt with in a piecemeal fashion (questions about whether epistemic rationality is permissive, and questions about the extent to which we can provide independent justification for our most fundamental epistemic standards). Nonetheless, it seems to me that those who are inclined to respond to the inconsistent triad by denying Rational Arbitrariness eventually owe a story about where the different arguments for Rational Arbitrariness go wrong. Simply insisting on our intuitions in support of Immodesty and No Luck isn't going to cut it.

\section{Conclusion}

I had two main goals in this paper. The first goal was to bring out a joint inconsistency between three individually attractive claims: Rational Arbitrariness, Immodesty, and No Luck. The second goal was to evaluate different possible responses to this inconsistent triad. As we've seen, each response comes with its own distinctive challenges, which call out for further investigation. As things stand, my own sympathies tend towards denying Rational Arbitrariness, though I haven't tried to argue that this response is more attractive than the alternatives. My more limited hope is that the reader will at least come away with an appreciation of the tension at hand, and perhaps with a sense of how to make further inroads into the question of how to resolve it.

\footnotetext{
33 Somewhat relatedly, Elga (ms., pp. 6-8) offers a diagnosis of the "unsettling feeling" we get when we discover that our epistemic standards have been influenced by arbitrary factors. Very roughly, Elga suggests that such a discovery merely makes salient a general skeptical worry, which was present all along. Schechter (ms., \4) raises some potential worries about this diagnosis. But in any case, what we're looking for here is not an explanation of why we'd be inclined to think (mistakenly) that arbitrary influences on our epistemic standards are a cause for concern. Rather, we're looking for an explanation of why we'd be inclined to think that self-ascriptions of epistemic luck are irrational, when in fact they needn't be.
} 
Acknowledgments: An earlier version of this paper was presented at the Asian Epistemology Network. I'd like to thank the audience on that occasion for constructive feedback. Thanks also to Zach Barnett, Ben Blumson, Han Li, Michael Pelczar, Richard Pettigrew, Lavinia Picollo, Abelard Podgorski, Eyal Tal, Weng Hong Tang, Dan Waxman, and an anonymous referee for Episteme for helpful comments and suggestions. This research was supported by a Tier 1 research grant from the Ministry of Education, Singapore.

\section{References}

Ballantyne, N. \& E. Coffman (2012): "Conciliationism and Uniqueness." In: Australasian Journal of Philosophy 90, pp. 657-70.

BonJour, L. (1980): "Externalist Theories of Empirical Knowledge." In: Midwest Studies in Philosophy 5, pp. 53-73.

Builes, D., S. Horowitz, and M. Schoenfield (2020): "Dilating and Contracting Arbitrarily." In: Noûs. Online first.

Campbell-Moore, C. and B. Levinstein (2021): "Strict Propriety is Weak." In: Analysis 81, pp. 8-13.

Cohen, G.A. (2000): If You're an Egalitarian, How Come You're so Rich?, Harvard University Press, Cambridge, Massachusetts.

Cohen, S. (2013): "A Defense of the (Almost) Equal Weight View." In The Epistemology of Disagreement, D Christensen \& J. Lackey (eds.), pp. 98-119. Oxford University Press.

Cohen, S. (1984): “Justification and Truth.” In: Philosopbical Studies 110, pp. 249-66.

Dogramaci, S. and S. Horowitz (2016): "An Argument for Uniqueness About Evidential Support.” In: Philosophical Issues 26, pp. 130-47.

Elga, A. (ms.): "Lucky to Be Rational." Unpublished manuscript presented at the Bellingham Summer Philosophy Conference 2008.

Elga, A. (2010): “Subjective Probabilities Should Be Sharp.” In: Philosophers' Imprint 10, pp. 1 11.

Feldman, R. (2007): “Reasonable Religious Disagreements.” In L. Antony (ed.), Philosophers Without Gods, pp. 194-214. Oxford: Oxford University Press.

Goldman, A. (1979): “What Is Justified Belief?” In G. Pappas (ed.), Justification and Knowledge, Boston: D. Reidel.

Greaves, H., \& D. Wallace (2006): "Justifying Conditionalization: Conditionalization Maximizes Expected Epistemic Utility.” In: Mind 115, pp. 607-32.

Jackson, E. (2019): “A Defense of Intrapersonal Belief Permissivism.” In: Episteme. Online first.

Joyce, J. (1998): “A Nonpragmatic Vindication of Probabilism.” In: Philosophy of Science 65, pp. $575-603$.

Joyce, J. (2005): “How Probabilities Reflect Evidence.” In: Philosophical Perspectives, $19 \mathrm{~m}$ pp. $153-78$. 
Kelly, T. (2013): “Evidence Can Be Permissive.” In M. Steup and J. Turri (eds.), Contemporary Debates in Epistemology. Blackwell.

Levi, I. (1985): "Imprecision and Indeterminacy in Probability Judgment." In: Philosophy of Science 52, pp. 390-409.

Lewis, D. (1971): “Immodest Inductive Methods.” In: Philosophy of Science 38, pp. 54-63.

Li, H. (2018): “A Theory of Epistemic Supererogation.” In: Erkenntnis 83, pp. 349-67.

Li, H. (2019a): "How Supererogation Can Save Intrapersonal Permissivism." In: American Philosophical Quarterly 56, pp. 171-86.

Li, H. (2019b): “The Trouble With Having Standards.” In: Philosophical Studies 176, pp. 1225 45.

Mayo-Wilson, C. and Wheeler G. (2016): "Scoring Imprecise Credences: A Mildly Immodest Proposal." In: Philosophy and Phenomenological Research 93, pp. 55-78.

Meacham, C. (2013): “Impermissive Bayesianism.” In: Erkenntnis 79, pp. 1185-1217.

Pettigrew, R. (ms.): Epistemic Risk and the Demands of Rationality. Unpublished manuscript.

Pettigrew, R. (forthcoming): "Accuracy-first Epistemology Without Additivity." To appear in Philosophy of Science.

Pettigrew, R. (2016): Accuracy and the Laws of Credence. Oxford: Oxford University Press.

Pettigrew, R. (2011): “An Improper Introduction to Epistemic Utility Theory.” In: Proceedings of EPS A: Amsterdam 09, H. de Regt, S. Hartmann, and S. Okasha (eds.). Springer.

Podgorski, A. (2016): “Dynamic Permissivism.” In: Philosophical Studies 173, pp. 1923-39.

Pritchard, D. (2005): Epistemic Luck. Oxford: Oxford University Press.

Pryor, J. (2000): “The Skeptic and the Dogmatist.” In: Noûs 34, pp. 517-49.

Rosen, G. (2001): "Nominalism, Naturalism, Epistemic Relativism." In: Philosophical Perspectives 15, pp. 69-91.

Schechter, J. (2013): "Rational Self-Doubt and the Failure of Closure." In: Philosophical Studies 163, pp. 429-52.

Schechter, J. (ms.): “Luck, Rationality, and Explanation: A Reply to Elga's 'Lucky to Be Rational'." Presented at the Bellingham Summer Philosophy Conference 2008.

Schoenfield, M. (forthcoming): "Meditations of Beliefs Formed Arbitrarily." Forthcoming in Oxford Studies in Epistemology.

Schoenfield, M. (2017): “The Accuracy and Rationality of Imprecise Credences." In: Noûs 51, pp. 667-85.

Schoenfield, M. (2014): "Permission to Believe: Why Permissivism Is True and What It Tells Us About Irrelevant Influences on Belief.” In: Noûs 48, pp. 193-218.

Schultheis, G. (2018): “Living on the Edge: Against Epistemic Permissivism.” In: Mind 127, pp. 863-79.

Smith, J. (2020): “Unacknowledged Permissivism.” In: Pacific Philosophical Quarterly 101, pp. $158-83$.

Titelbaum, M. \& M. Kopec (ms.): "Plausible Permissivism.” Unpublished manuscript.

Unger, P. (1968): “An Analysis of Factual Knowledge.” In: The Journal of Philosophy 65, pp. $157-70$. 
van Fraassen, B. (1990): "Figures in a Probability Landscape.” In J. Dunn \& A. Gupta (eds.), Truth or Consequences. Dodrecht: Kluwer, pp. 345-56.

Vavova, K. (2018): “Irrelevant Influences." In: Philosophy and Phenomenological Research 96, pp. 134-52.

White, R. (2005): “Epistemic Permissiveness.” In: Philosophical Perspectives 19, pp. 445-59.

White, R. (2010): “You Just Believe That Because...” In: Philosophical Perspectives 19, pp. 44559.

Wright, C. (2004): “Warrant for Nothing (and Foundations for Free)?” In: Aristotelian Society Supplementary Volume 78, pp. 167-212.

Ye, Ru (2019): “The Arbitrariness Objection Against Permissivism.” In: Episteme. Online first.

Zagzebski, L. (1994): “The Inescapability of Gettier Problems.” In: The Philosophical Quarterly 44, pp. 65-73. 